\title{
Mouse Lymphoma L1210 Cells Can Be Arrested in the G1 Phase by Adjusting Cellular Cysteine and Glutathione
}

\author{
Tetsuro Ishii, Takeshi Todoroki ${ }^{1}$, Akira Takada ${ }^{1}$ and Yoshiki Sugita \\ Department of Biochemistry and Department of Surgery ${ }^{1}$, Tsukuba University \\ School of Medicine, Sakura-mura, Niihari-gun, Ibaraki-ken 305, Japan
}

\begin{abstract}
Mouse lymphoma L1210 cells (NCI line) that have low ability to take up cystine became deficient in cellular cysteine and glutathione in normal culture media. The cells entered the resting state during culture when they were seeded at high cell densities. They remained viable and were mostly present in the G1 or G0 phase. In the growth-arrested state, the cellular glutathione content was one order of magnitude lower than in the exponentially growing phase in the presence of 2-mercaptoethanol. In the arrested state, DNA synthesis was almost inhibited, and RNA and protein synthesis decreased markedly. Transfer of the cells to medium containing 2-mercaptoethanol, which improves the utilization of cystine by these cells, produced the rapid recovery of RNA and protein synthesis. DNA synthesis slowly increased, reaching a maximum after a lag period.
\end{abstract}

We previously showed that the growth defect of mouse lymphoma L1210 cells in vitro is caused by the low ability of these cells to take up cystine which is an essential amino acid in the cells $(9,10)$. Feeder layer cells support growth of L1210 cells by providing cysteine continuously (9). Since the research reported by Broome and Jeng (5), 2-mercaptoethanol has been used routinely to maintain L1210 cells in vitro. We also showed that 2-mercaptoethanol supports cell growth by reacting with cystine to produce cysteine plus a mixed disulfide of cysteine and 2-mercaptoethanol in the culture medium. These two products are readily taken up by the cells, the mixed disulfide being assimilated mainly through the L system (10). L1210 cells, therefore, provide an excellent system with which to study the roles of cysteine and glutathione in growth and other cellular activities.

We found an interesting relation for cell density, viability and glutathione content. Cells survived well at high cell densities in the absence of 2-mercaptoethanol; when L1210 cells were transferred to culture medium without 2-mercaptoethanol, the glutathione content decreased markedly within a few hours (9). We observed that the rate of glutathione decrease depended on cell density, being slower at high densities. A possible explanation of this phenomenon is that at high cell densities a small amount of cysteine leaks from the cells and accumulates in the medium (9) which may slow down the rate of cellular cysteine leaking into the medium. That

Abbreviations used: DMEM, Dulbecco's Modification of Eagle's Medium; PBS (-), $\mathrm{Ca}^{2+}$, $\mathrm{Mg}^{2+}$-free phosphate-buffered saline. 
would be why a high cell density seems necessary for the maintenance of the minimum glutathione level needed for the survival of the cells.

The culture conditions used to obtain a growth-arrested cell population are as follows: Cells that had been grown in Dulbecco's Modification of Eagle's Medium (DMEM) supplemented with $10 \%$ calf serum and $20 \mu \mathrm{M}$ 2-mercaptoethanol were collected, then washed and suspended at a cell density of $2 \times 10^{6}$ cells $/ \mathrm{ml}$ in culture medium without 2-mercaptoethanol. Cell number was counted with a hemocytometer. Cell viability was estimated by the nigrosine $(0.05 \%)$ exclusion method. The cell number increased $10-30 \%$ in the first $24 \mathrm{~h}$ and viability remained above $90 \%$ for at least $48 \mathrm{~h}$. We measured the total (reduced and oxidized) glutathione contents using the enzymic method of Teitze (18) because the glutathione contents reflect the content of cysteine which technically is difficult to determine. Under these culture conditions, cellular glutathione decreased to $1.3 \mathrm{nmol} / \mathrm{mg}$ cell protein by the 24th hour, which is markedly low in comparison to the value of $3-7 \mathrm{nmol} / \mathrm{mg}$ cell protein for exponentially growing cells in the presence of $10 \mu \mathrm{M}$ 2-mercaptoethanol (9).

As Broome and Jayaram (4) reported, when cells were transferred to culture medium without 2-mercaptoethanol the incorporation of $\mathrm{L}-\left[{ }^{3} \mathrm{H}\right]$ leucine, $\left[{ }^{3} \mathrm{H}\right]$ uridine

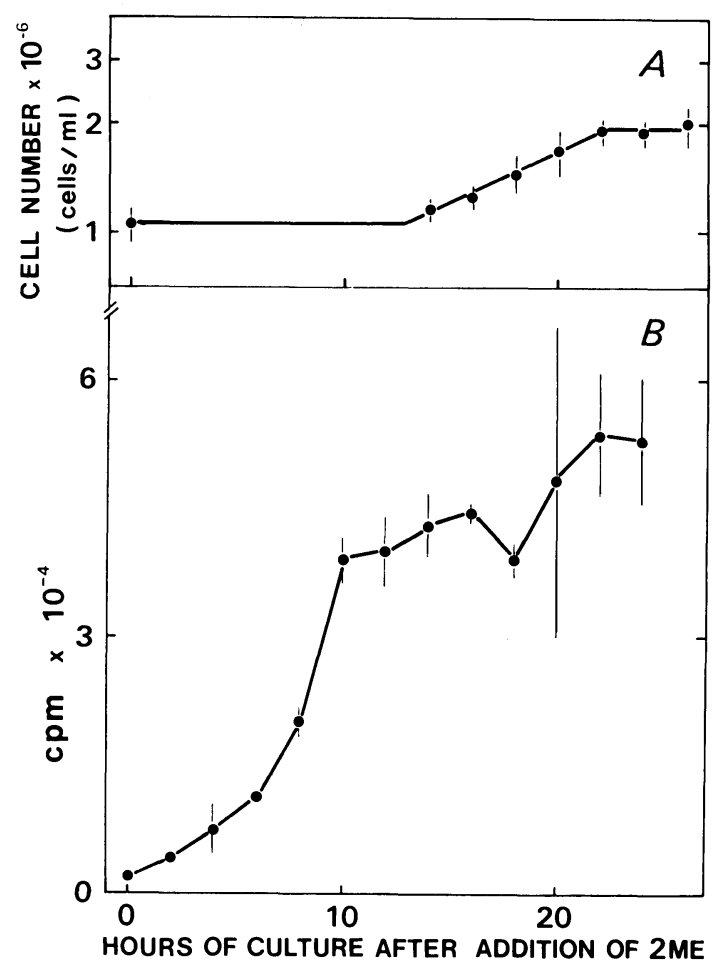

Fig. 1. Kinetics of cell growth (A) and thymidine incorporation into L1210 cells (B) after growtharrested cells were transferred at time 0 to fresh culture medium containing $20 \mu \mathrm{M}$ 2-mercaptoethanol (2ME). The growth arrested cells were transferred to culture medium containing $20 \mu \mathrm{M} 2$-mercaptoethanol and seeded at $10^{6} \mathrm{cells} / \mathrm{ml}$. Values given are averages of triplicate experiments \pm standard deviation (bar). Each sample of $3 \times 10^{6}$ cells was incubated in a plastic culture tube until the time indicated, then the incorporation of thymidine $(1 \mu \mathrm{Ci})$ was measured. Labeling time was $20 \mathrm{~min}$. 
and $\left[{ }^{3} \mathrm{H}\right]$ thymidine into the cells gradually decreased. The incorporation of leucine decreased gradually to half the initial value after $20 \mathrm{~h}$. Uridine and thymidine incorporation gradually decreased, respectively reaching 30 and $2 \%$ of the initial incorporation after $20 \mathrm{~h}$, evidence that DNA synthesis had almost ceased.

Using growth-arrested L1210 cells we examined the recovery of protein and RNA and DNA synthesis after transfer to medium containing 2-mercaptoethanol. Cells were transferred to medium supplemented with $20 \mu \mathrm{M}$ 2-mercaptoethanol and seeded at a density of $10^{6}$ cells $/ \mathrm{ml}$. Initially increases in both RNA and protein syntheses were found. In contrast, DNA synthesis remained low in comparison to that found under conditions for experimental growth. The incorporation of thymidine reached its maximum 10-16 h after transfer (Fig. 1B). The glutathione content was restored to $10 \mathrm{nmol} / \mathrm{mg}$ cell protein within $1 \mathrm{~h}$, and at $8 \mathrm{~h}$ reached the stationary value of about $30 \mathrm{nmol} / \mathrm{mg}$ cell protein. There was a lag period of about $13 \mathrm{~h}$ before the start of cell division. The cell number was nearly double within $22 \mathrm{~h}$ when cells were seeded at a density of $10^{6}$ cells/ml (Fig. 1A).

The distributions of cells throughout different phases of the cell cycle after growtharrested cells had been transferred to new medium containing 2-mercaptoethanol are shown in Fig. 2, the distributions of the growth-arrested cells and the exponentially growing cells being given in $(0 \mathrm{~h})$. During incubation in medium without 2-mercaptoethanol, the cells in G1 increased markedly, whereas the cells in S and G2+M decreased. Because some cells remained in the S phase, the G1 block seems to be leaky, as has been noted in the amino acid starvation in 3T3 cells (8).

The extent of the G1 arrest of L1210 cells under these conditions is comparable to the G1 arrest in other cell lines. At $8 \mathrm{~h}$, cells in S phase began to increase. At $12 \mathrm{~h}$, the majority of the cells were in $\mathrm{S}$ phase. At $16 \mathrm{~h}$, cells in the $\mathrm{G} 2+\mathrm{M}$ phase had reached a maximum. At $19 \mathrm{~h}$, the cells in G1 again increased, and by the $22 \mathrm{nd}$ hour the second cell cycle appeared to be starting. These results indicate that L1210 cells retain the ability to enter the resting state when intracellular concentrations of glutathione and cysteine are limited and that they start to divide again in a partially synchronized fashion in the presence of 2-mercaptoethanol.

Recently, a transport system, highly specific to cystine and glutamate, has been found and characterized $(2,3)$. This system appears to be closely related to glutathione metabolism. The L1210 cells, which lack this system, become deficient in cysteine but not in glutamate. Although DMEM medium contains no glutamate, the cellular glutamate concentration is adequate for growth (9) because it is synthesized intracellularly. But, the cysteine in L1210 cells is not synthesized effectively from methionine (13).

The results of growth control of L1210 cells that is induced by glutathione and cysteine deficiencies are 1. the accumulation of cells in G1 (or G0) phase; 2. recovery and traverse of the cell cycle due to restoration of the supply of cysteine to cells mediated by 2-mercaptoethanol; 3. rapid recovery of RNA and protein syntheses; 4. a lag time until the rapid increase of DNA synthesis takes place and 5. partially synchronized cell division. These coordinated responses of metabolic reactions correspond to the "pleiotypic response" (7) commonly found in "normal" cells when certain amino acids are limited and refed, i.e., deficiencies in isoleucine and glutamine for Chinese hamster cells (12) and other mammal an cell lines (19), in tryptophan for LM-cells (6) and in serine for BHK cells (1).

Cystine and glutamine are required to reinitiate DNA synthesis in 3T3 cells whose 


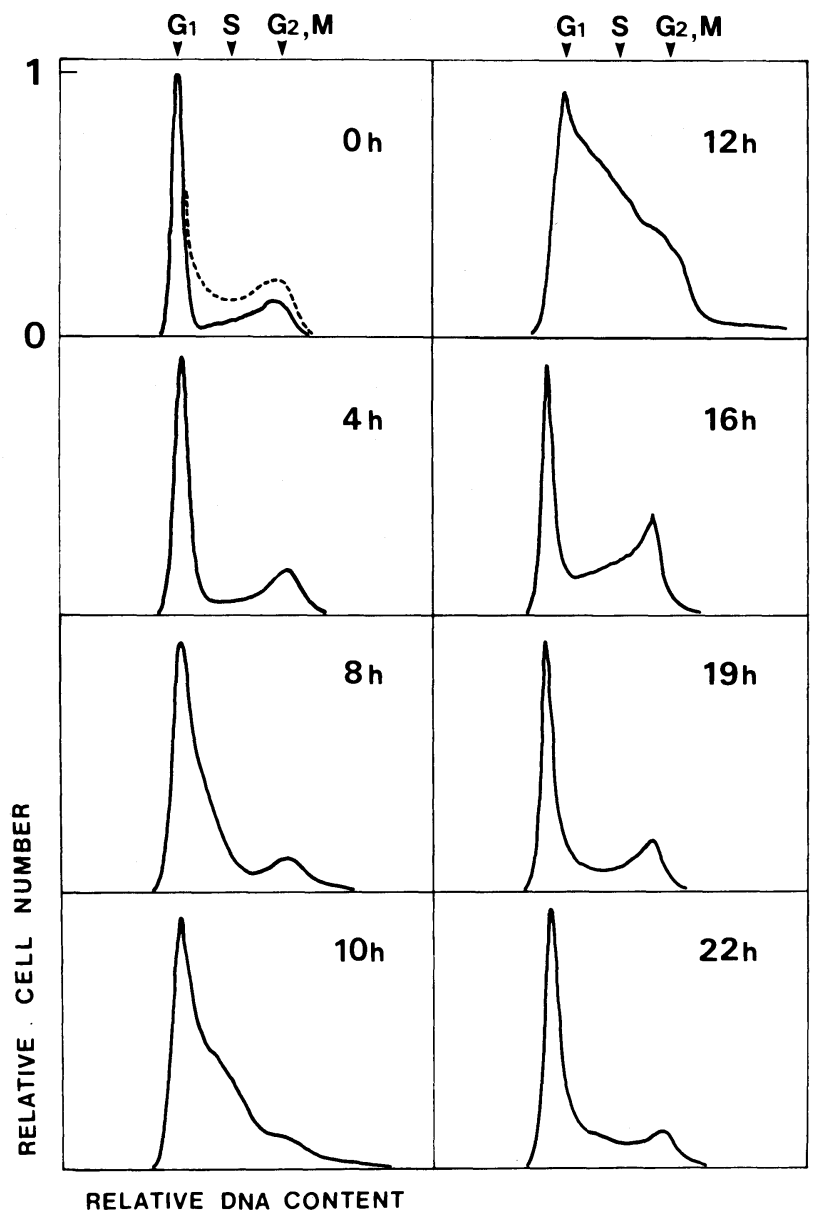

Fig. 2. Kinetics of change in cell cycle distribution after growth-arrested L1210 cells had been transferred to medium containing 2-mercaptoethanol.

The growth-arrested cells were transferred and seeded at $10^{6} \mathrm{cells} / \mathrm{ml}$ in the culture medium containing $20 \mu \mathrm{M}$ 2-mercaptoethanol. The dotted line at $0 \mathrm{~h}$ shows the cell cycle distribution of growing cells in the presence of 2-mercaptoethanol. Cells were washed once with PBS $(-)$ then treated by the method described by Krishan (11). Cells stained with propidium iodide were analyzed in FACS IV (Becton Dickinson).

growth has been arrested by amino acid limitation (8). Malignant or transformed cells are known to be less sensitive than normal cells to growth limitations imposed by lack of nutrients and/or serum or by overcrowding (see the review by Pardee et al., (16)). For example, growth of SV40 virus-transformed 3T3 cells is retarded by a leucine limitation, but the cells remain arrested throughout the cell cycle (17). Chemically transformed mouse cells, unlike DNA virus-transformed cells, become quiescent in $\mathrm{Gl}$ due to depletion of certain amino acids $(14,15)$. The pleiotypic response described here caused by a cyst(e)ine limitation in L1210 cells is, therefore, a good model with which to study the growth control in malignant cells. 
Acknowledgments. We are grateful to Dr. Shiro Bannai and Dr. Victor M. Darley-Usmar for their stimulating discussions of our research, to Dr. Yasushi Miyoshi for checking the mycoplasma contamination in our cells, to Dr. Tazuko Tashiro for providing the L1210 cells and to Miss Mari Sugawara for her excellent technical assistance.

\section{REFERENCES}

1. Allen, R.W. and M. Moskowitz. Arrest of cell growth in the G1 phase of the cell cycle by serine deprivation. Exp. Cell Res. 116, 127-137, 1978

2. Bannai, S. and E. Kitamura. Transport interaction of L-cystine and L-glutamate in human diploid fibroblasts in culture. J. Biol. Chem. 255, 2372-2376, 1980

3. Bannai, S. and E. Kitamura. Role of proton dissociation in the transport of cystine and glutamate in human diploid fibroblasts in culture. J. Biol. Chem. 256, 5770-5772, 1980

4. BROOME, J.D. and H.N. JAYARAM. Studies of the mechanism of growth promotion of lymphoma cells by 2-mercaptoethanol in vitro. Acta Neuropath. (Berlin), Suppl. VI, 41-45, 1975

5. Broome, J.D. and M.W. Jeng. Promotion of replication in lymphoid cells by specific thiols and disulfides in vitro. J. Exp. Med. 138, 574-592, 1973

6. BRUnNer, M. Regulation of DNA synthesis by amino acid limitation. Cancer Res. 33, 29-32, 1973

7. Hershko, A., P. Mamont, R. Shields and G.M. Tomkins. Pleitoypic Response. Nature New Biol. 232, 206-211, 1971

8. Holley, R.W. and J.A. Kiernan. Control of the initiation of DNA synthesis in 3T3 cells: low-molecular-weight nutrients. Proc. Natl. Acad. Sci. U.S.A. 71, 2942-2945, 1974

9. IshiI, T., I. Hishinuma, S. Bannai and Y. Sugita. Mechanism of growth promotion of mouse lymphoma L1210 cells in vitro by feeder layer or 2-mercaptoethanol. J. Cell. Physiol. 107, 283293, 1981

10. IsHII, T., S. BANNAI and Y. SugITA. Machanism of growth stimulation of L1210 cells by 2mercaptoethanol in vitro. Role of the mixed disulfide of 2-mercaptoethanol and cysteine. J. Biol. Chem. 256, 12387-12392, 1981

11. Krishan, A. Rapid flow cytofluorometric analysis of mammalian cell cycle by propidium iodide staining. J. Cell Biol. 66, 188-193, 1975

12. LEY, K.D. and R.A. TOBEY. Regulation of initiation of DNA synthesis in Chinese hamster cells. II. Induction of DNA synthesis and cell division by isoleucine and glutamine in G1-arrested cells in suspension culture. J. Cell Biol. 47, 453-459, 1970

13. Livingston, D.M., C. Ferguson, R. Gollogly and H. Lazarus. Accumulation of cystine auxotrophic thymocytes accompanying type $\mathrm{C}$ viral leukemogenesis in the mouse. Cell 7 , 41-47, 1976

14. Moses, H.L., J.A. Proper, M.E. Volkenant and D.E. Swartzendruber. Growth arrest of AKR-2B cells maintained in the presence of epidermal growth factor or 12-0-tetradecanoylphorbol-13 acetate: evidence for two separate G1 arrest points. J. Cell. Physiol. 102, 367-378, 1980

15. Moses, H.L., J.A. Proper, M.E. Volkenant, D.J. Wells and M.J. Getz. Mechanism of growth arrest of chemically transformed cells in culture. Cancer Res. 38, 2807-2812, 1978

16. Pardee, A.B., R. Dubrow, J.L. Hamlin and R.F. Kletzien. Animal cell cycle. Ann. Rev. Biochem. 47, 715-750, 1978

17. PAUL, D. Quiescent SV40 virus transformed 3 T3 cells in culture. Biochem. Biophys. Res. Commun. 53, 745-753, 1973

18. TIETZE, E. Enzymic method for quantitative determination of nanogram amounts of total and oxidized glutathione: application to mammalian blood and other tissues. Anal. Biochem. 27, 502-522, 1969

19. ToвEY, R.A. and K.D. LEY. Isoleucine-mediated regulation of genome replication in various mammalian cell lines. Cancer Res. 31, 46-51, 1971

(Received for publication, February 13, 1985) 